\title{
Streptococcus pneumoniae: evolución de los serotipos y los patrones de susceptibilidad antimicrobiana en aislamientos invasores en 11 años de vigilancia en Colombia (1994 -2004)
}

Clara Inés Agudelo ${ }^{1}$, Jaime Moreno ${ }^{1}$, Olga Marina Sanabria ${ }^{1}$, María Victoria Ovalle ${ }^{1}$, José Luís Di Fabio ${ }^{2}$, Elizabeth Castañeda ${ }^{1}$ y Grupo Colombiano de Trabajo en Streptococcus pneumoniae ${ }^{3}$.

${ }_{1}^{1}$ Grupo de Microbiología, Instituto Nacional de Salud, Bogotá D.C., Colombia.

2 Organización Panamericana de la Salud, Washington D. C., EE UU.

${ }^{3}$ Grupo Colombiano de Trabajo en Streptococcus pneumoniae: Bogotá: Sandra Nuñez, LSP; Patricia Rincón y Jaime Patiño, Hospital de la Misericordia; Martha Uzeta, Clínica del Niño del ISS; Nidia Torres, Hospital Universitario San Ignacio; Mónica Gutiérrez y Clara Luz Rico, Fundación Santa Fe de Bogotá; Edilma Torrado, Clínica Reina Sofía; Romelia Villa, Hospital de Kennedy; María Constanza Correa, Hospital Simón Bolívar; Stella Mariño, Hospital de La Victoria; Gloría Inés Gallo, Hospital Santa Clara; Claudia Cecilia Dueñas, Clínica Colsubsidio; Claudia Fajardo, Hospital San José. Antioquia: Hilda Álvarez, LSP; Sergio Jaramillo, Hospital Pablo Tobón Uribe. Santander: Vianey Portilla, LSP y Martha Jácome, Hospital Ramón González Valencia. Risaralda: Mercedes Cano, LSP; Miriam Gómez y Yolanda Celis, Hospital San Jorge. Valle: Martha Gartner, LSP; Nancy Villamarín y Luz Marina Gallardo, Hospital Universitario del Valle; Adriana Rodríguez, Hospital Infantil Club Noel; Claudia Rocio Castañeda, Fundación Valle de Líli. Caldas: Alberto de la Ossa, LSP; Carolina Villegas y Cecilia López, Hospital Infantil Universitario de la Cruz Roja. Norte de Santander: Gladys Mora, LSP; Myrian Laguado, Hospital Erasmo Meoz de Cúcuta. Tolima: Martha Gómez, Hospital Federico Lleras Acosta. Magdalena: Mileny Arragocés, LSP; Córdoba: Salim Mattar, Universidad de Córdoba; Cartagena: Wilfrido Coronel, Hospital de Bocagrande.

Introducción. Streptococcus pneumoniae es una las principales causas de morbilidad y mortalidad en niños y adultos en el mundo.

Objetivo. Realizar un análisis de los datos de la vigilancia por el laboratorio de los aislamientos invasores de S. pneumoniae recuperados entre 1994 y 2004.

Materiales y métodos. Se empleó la información de los aislamientos invasores de $S$. pneumoniae recibidos en el Grupo de Microbiología del Instituto Nacional de Salud durante la vigilancia de meningitis bacteriana aguda e infección respiratoria aguda entre 1994 y 2004. Los aislamientos contaban con datos epidemiológicos, serotipo, patrones de susceptibilidad antimicrobiana y algunos con tipificación molecular.

Resultados. Se analizaron los datos de 2.022 aislamientos procedentes de 120 hospitales de diferentes regiones del país, recuperados principalmente de hemocultivos $(50,7 \%)$ y líquido cefalorraquídeo (42\%). Los serotipos más importantes fueron el 14, 6B, 23F, 1, 5, 6A, 19F, 18C y $9 \mathrm{~V}$, los cuales corresponden al $83,6 \%$ en niños menores de 6 años, al $74,0 \%$ en el grupo de 6 a 14 años y al $61,4 \%$ en mayores de 14 años. El 29,8\% de los aislamientos presentó susceptibilidad disminuida a la penicilina (SDP), 44,3\% a trimetoprim-sulfametoxazol, $32,4 \%$ a tetraciclina, $8,2 \%$ a cloranfenicol, $3,8 \%$ a eritromicina; todos fueron sensibles a vancomicina y el $13 \%$ fue multirresistente. Se tipificaron 602 aislamientos con SDP, de los cuales $27(4,5 \%)$ se relacionaron con el clon 1-España ${ }^{23 F}, 38(6,3 \%)$ con el clon 2-España ${ }^{6 B}, 301(50 \%)$ con el 3España $^{9 \mathrm{~V}}$ y $75(12,5 \%)$ con el clon 26 -Colombia ${ }^{23 F}$, además, los 138 aislamientos con tipo capsular 5 se relacionaron con el clon $19-$ Colombia $^{5}$.

Conclusiones. Los resultados proporcionan información básica necesaria para el diseño e implementación de estrategias para la prevención de la enfermedad neumocócica en nuestro país.

Palabras clave: Streptococcus pneumoniae, infecciones neumocócicas, meningitis, neumonía, resistencia a las drogas. 


\section{Streptococcus pneumoniae: serotype evolution and patterns of antimicrobial susceptibility in invasive isolates from 11 years surveillance $(1994-2004)$ in Colombia}

Background. Streptococcus pneumoniae is an important cause of morbidity and mortality in children and adults in the world.

Objective. Analysis of data from laboratory surveillance of S. pneumoniae, invasive isolates recovered from 1994 to 2004.

Materials and methods. Database of invasive isolates of $S$. pneumoniae, sent to the Microbiology Group through the national surveillance laboratory network of acute bacterial meningitis and acute respiratory infections, from 1994 to 2004. The isolates had epidemiological data, serotyping, antimicrobial susceptibility patterns and some of them molecular typing.

Results. The data of 2,022 isolates from 120 hospitals of different regions of the country were analyzed. The isolates were recovered mainly from blood cultures (50.7\%) and cerebrospinal fluid (42\%). The most important serotypes were 14, 6B, 23F, 1, 5, 6A, 19F, 18C y 9V, which account for $83.6 \%$ of isolates obtained from children under 6 years of age, $74 \%$ from the $6-14$ year age group and $61.4 \%$ from children over 14 years of age. Overall, $29.8 \%$ of isolates presented diminished susceptibility to penicillin (DSP), 44.3\% to trimethoprimsulphamethoxazole, $32.4 \%$ to tetracycline, $8.2 \%$ to chloramphenicol and $3.8 \%$ to erythromycin. All isolates were susceptible to vancomycin and $13 \%$ were multiresistant. Six hundred two DSP isolates were molecularly typed, $27(4.5 \%)$, were related with the Spain ${ }^{23 F_{-}} 1$ clone, $38(6.3 \%)$ with the Spain ${ }^{6 \mathrm{~B}}-2$, 301 (50\%) with the Spain ${ }^{9 \mathrm{~V}}-3$ and 75 (12.5\%) with the Colombia ${ }^{23 \mathrm{~F}}-26$ clone. Moreover, all 138 isolates with capsular type 5 were related to the Colombia -19 clone.

Conclusion. The results provide basic information necessary to design and implement strategies for prevention of pneumococcal disease.

Keywords: Streptococcus pneumoniae, neumococcal infections, pneumonia, meningitis, drug resistance.

Las neumonías y meningitis causadas por Streptococcus pneumoniae son en la actualidad unas de las principales causas de morbilidad y mortalidad en la población en los extremos de la vida, tanto en países industrializados como en vías de desarrollo $(1,2)$.

En el 2003, en Colombia se presentaron cerca de 592.167 casos de infección respiratoria aguda (IRA) con una mortalidad en los menores de cinco años de $3,2 / 100.000$ niños $(3,4)$. Se estima que en el mundo la neumonía por $S$. pneumoniae causa 1,2 millones de muertes al año y $40 \%$ de ellas se presentan en menores de cinco años. En países en desarrollo $S$. pneumoniae es responsable de 70.000 muertes por meningitis y de un número similar por otras infecciones invasoras en el mismo grupo de edad (5).

\author{
Correspondencia: \\ Elizabeth Castañeda \\ Instituto Nacional de Salud. Avenida calle 26 No. 51-60 \\ Teléfono 57-1-220-0920 \\ Fax 57-1-220-0901 \\ ecastaneda@ins.gov.co
}

Recibido: 29/12/05; aceptado: 05/04/06
Adicionalmente, el incremento de la resistencia a los antibióticos de patógenos tanto de origen comunitario como intrahospitalario se ha convertido en un problema de salud pública reconocido por la Organización Mundial de la Salud (6). Específicamente en S. pneumoniae se ha descrito el aumento de la resistencia, especialmente a los B lactámicos (7), en Latinoamérica (8), España (9), Estados Unidos (10) y en los países asiáticos (11). La capacidad de adquirir resistencia a diferentes antibióticos hace que el tratamiento antimicrobiano de las infecciones causadas por $S$. pneumoniae sea cada vez más difícil, y la gran variedad de serotipos hace complicada y costosa la prevención por vacunación (2). Además, los patrones de susceptibilidad y los serotipos prevalentes varían de una región a otra, aún en áreas del mismo país (9), lo que hace necesario mantener una vigilancia por el laboratorio que permita conocer el comportamiento de $S$. pneumoniae a nivel no sólo del país sino de la región.

En 1994, a través del proyecto del Sistema Regional de Vacunas (SIREVA) de la Organización 
Panamericana de la Salud (OPS), se inició en Colombia la vigilancia de la distribución de los tipos capsulares y la susceptibilidad antimicrobiana de los aislamientos de $S$. pneumoniae causantes de enfermedad invasora en niños menores de 6 años $(8,12)$. A partir de 1996, el proyecto SIREVA se unió a la vigilancia por red de laboratorios de los patógenos causantes de meningitis bacteriana aguda (MBA) e IRA en la población general, conformando un único programa de vigilancia nacional que hace parte del proyecto Sistema de Redes de Vigilancia de los Agentes Bacterianos causantes de Neumonías y Meningitis (SIREVA II) de la OPS.

El objetivo de este trabajo fue realizar un análisis de los datos de la vigilancia por el laboratorio de los aislamientos invasores de $S$. pneumoniae recuperados de 1994 a 2004, tanto en población infantil como en adultos, con el fin de describir la evolución de los serotipos y patrones de susceptibilidad antimicrobiana de los aislamientos, las características demográficas y clínicas y la procedencia, y hacer un análisis general sobre la circulación de clones internacionales resistentes y su evolución durante el periodo estudiado, así como un análisis de la cobertura hipotética de las vacunas conjugadas.

\section{Materiales y métodos}

\section{Sistema de vigilancia}

La red de laboratorios para la vigilancia de la MBA e IRA y de otras enfermedades invasoras está conformada por 107 hospitales de segundo y tercer nivel ubicados en las capitales de los departamentos y en Bogotá, y por 30 hospitales de segundo nivel de otros municipios del país que realizan procedimientos de microbiología. Una vez obtenido el aislamiento es remitido al laboratorio de salud pública del departamento o distrito, donde se confirma el diagnóstico y se remite al Grupo de Microbiología del Instituto Nacional de Salud (INS); sin embargo, algunos hospitales privados remiten los aislamientos directamente al INS.

\section{Aislamientos}

Se incluyeron para el análisis los aislamientos invasores de $S$. pneumoniae recibidos en el Grupo de Microbiología entre 1994 y 2004 que tuvieran la información de edad, procedencia, diagnóstico y tipo de muestra (12). Los aislamientos se confirman y con ellos se realizan los estudios complementarios de serotipificación, susceptibilidad antimicrobiana y tipificación molecular de acuerdo con las técnicas estandarizadas a nivel regional (13-15).

\section{Confirmación y serotipificación}

Los aislamientos fueron confirmados con las técnicas de optoquina y solubilidad en bilis, estandarizadas durante el proyecto SIREVA en el Centro Nacional para Streptococcus (National Centre for Streptococcus, NCS) de Alberta, Canadá, centro internacional de referencia para el estudio y la serotipificación realizada con la reacción de Quellung (13). Los aislamientos se conservan a $-70^{\circ} \mathrm{C}$ en leche descremada al $20 \%$ (Difco).

\section{Susceptibilidad antimicrobiana}

La susceptibilidad antimicrobiana se determinó por el método de difusión de disco Kirby Bauer a penicilina (prueba tamiz con discos de oxacilina de $1 \mu \mathrm{g})$, trimetoprim-sulfametoxazol (SXT) $(1,25 /$ $23,7 \mu \mathrm{g})$, cloranfenicol $(30 \mu \mathrm{g})$, eritromicina $(15 \mu \mathrm{g})$, tetraciclina $(1 \mu \mathrm{g})$ y vancomicina $(30 \mu \mathrm{g})$, y la concentración inhibitoria mínima (CIM) en $\mu \mathrm{g} / \mathrm{ml}$, a penicilina, ceftriaxona, SXT, cloranfenicol, eritromicina, tetraciclina y vancomicina con la técnica de la microdilución en caldo. Los aislamientos de pacientes con neumonía mayores de 14 años tenían el dato de la sensibilidad a las fluoroquinolonas, detectada por la prueba de difusión de disco a ofloxacina $(5 \mu \mathrm{g})$ y por $\mathrm{CIM}$ a ciprofloxacina. Las pruebas de susceptibilidad antimicrobiana se realizaron e interpretaron de acuerdo con las recomendaciones del Comité Nacional para Estándares de Laboratorio Clínico (NCCLS), ahora Instituto para Estándares de Laboratorio Clínico (CLSI), y como cepa de referencia se utilizó S. pneumoniae ATCC 49619 $(14,15)$.

\section{Estudios moleculares}

Se recopiló y analizó la información de los estudios moleculares de los aislamientos de $S$. pneumoniae a los cuales se les había realizado la electroforesis de campo pulsado (PFGE) según el protocolo de 
Vela y col (16). Los patrones de las bandas se asignaron visualmente y se clasificaron según los criterios de Tenover (17); igualmente, se analizaron con el programa de cómputo Fingerprinting II (Bio-Rad) para determinar el porcentaje de similitud genética de los aislamientos. También se utilizó la información de 253 aislamientos con SDP que tenían los perfiles de restricción de las proteínas de unión a penicilina (PBP) 1a, 2b y 2x.

\section{Control de calidad}

La calidad de los resultados es validada por el programa internacional de evaluación externa del desempeño liderado por el NCS de Alberta, Canadá, que incluye las pruebas confirmatorias, la serotipificación y las pruebas de susceptibilidad antimicrobiana, difusión de disco y CIM.

\section{Análisis de los datos}

El análisis de los datos se realizó con el programa EPI-Info versión 6,04. Para determinar las diferencias estadísticas de las prevalencias se utilizó el test de Fisher (18).

Para comparar la distribución de los serotipos y la frecuencia de la resistencia se dividió la población en tres grupos de edad, menores de seis años, de 6 a 14 años y mayores de 14 años. Para algunos de los análisis, el grupo de los menores de seis años se subdividió en menores de dos y seis meses y menores de dos años, y el grupo de mayores de 14 años se subdividió en grupos de 15 a 50, 51 a 65 y mayores de 65 años. El análisis de la evolución de los serotipos y la susceptibilidad antimicrobiana a penicilina se hizo por períodos de dos años hasta el 2001 y luego del 2002 al 2004. Para el análisis de la distribución de los serotipos y la frecuencia de SDP por procedencia, se utilizaron los datos del Distrito Capital y de los cuatro departamentos que enviaron el mayor número de aislamientos.

Para determinar la cobertura potencial de las vacunas conjugadas heptavalente, de diez serotipos y de 13 serotipos, se hizo un análisis teórico para el cual se empleó la frecuencia de aislamientos de los serotipos incluidos en la vacuna en los menores de seis años.

\section{Resultados}

\section{Características demográficas}

De 1994 a 2004 se recibieron en el Grupo de Microbiología 2.022 aislamientos de $S$. pneumoniae de 23 Laboratorios de Salud Pública Departamentales y del Distrito Capital. Del total de aislamientos, 1.496 (74\%) eran de 34/137 $(24,8 \%)$ hospitales que participan regularmente en la vigilancia. La procedencia de los aislamientos fue como sigue: de Bogotá, 876 (43,3\%), de Antioquia, 458 (22,7\%), del Valle, $267(13,2 \%)$, de Santander, 133 (6,6\%), de Risaralda, 113 $(5,6 \%)$, de Caldas, 50 (2,5\%), de Norte de Santander, 29 (1,4\%), de Tolima, $19(0,9 \%)$ y de Córdoba, 14 (0,7\%); los 63 (3,1\%) aislamientos restantes fueron enviados por 16 departamentos (rango de uno a nueve por departamento).

La distribución de los 2.022 aislamientos por grupos de edad y año de recuperación se consigna en el cuadro 1. De 1.986 aislamientos que tenían el dato de género, $1.216(61,2 \%)$ eran de pacientes del sexo masculino y $770(38,8 \%)$ del femenino $(p<0,001)$. La distribución por género fue similar en los diferentes grupos de edad estudiados.

\section{Características clínicas}

Los aislamientos fueron recuperados de las siguientes muestras: $1.026(50,7 \%)$ de

Cuadro 1. Distribución de los aislamientos de Streptococcus pneumoniae por grupos de edad y año de recuperación, 1994-2004.

\begin{tabular}{|c|c|c|c|c|c|c|c|}
\hline \multirow{3}{*}{$\begin{array}{l}\text { Año } \\
1994\end{array}$} & \multicolumn{6}{|c|}{ Grupos de edad en años } & \multirow[b]{2}{*}{ Total } \\
\hline & \multicolumn{2}{|c|}{$<6$} & \multicolumn{2}{|c|}{$\begin{array}{c}6-14 \\
\text { n (\%) }\end{array}$} & \multicolumn{2}{|c|}{$>14$} & \\
\hline & 139 & $(83,7)$ & 19 & $(11,5)$ & 8 & $(4,8)$ & 166 \\
\hline 1995 & 168 & $(94,9)$ & 3 & $(1,7)$ & 6 & $(3,4)$ & 177 \\
\hline 1996 & 100 & $(79,4)$ & 10 & $(7,9)$ & 16 & $(12,7)$ & 126 \\
\hline 1997 & 98 & $(67,6)$ & 14 & $(9,7)$ & 33 & $(22,7)$ & 145 \\
\hline 1998 & 74 & $(53,6)$ & 12 & $(8,7)$ & 52 & $(37,7)$ & 138 \\
\hline 1999 & 89 & $(55,6)$ & 23 & $(14,4)$ & 48 & $(30,0)$ & 160 \\
\hline 2000 & 96 & $(48,5)$ & 24 & $(12,1)$ & 78 & $(39,4)$ & 198 \\
\hline 2001 & 104 & $(47,7)$ & 29 & $(13,3)$ & 85 & $(39,0)$ & 218 \\
\hline 2002 & 117 & $(48,8)$ & 24 & $(10,0)$ & 99 & $(41,2)$ & 240 \\
\hline 2003 & 94 & $(47,7)$ & 19 & $(9,6)$ & 84 & $(42,7)$ & 197 \\
\hline 2004 & 114 & $(44,4)$ & 35 & $(13,6)$ & 108 & $(42,0)$ & 257 \\
\hline Total & 1193 & $(59,0)$ & 212 & $(10,5)$ & 617 & $(30,5)$ & 2022 \\
\hline
\end{tabular}


hemocultivos, $849(42,0 \%)$ de líquido cefalorraquídeo, 118 (5,8\%) de líquido pleural y $29(1,5 \%)$ de otros líquidos corporales; 901 $(44,6 \%)$ eran de pacientes con meningitis, 861 $(42,6 \%)$ con neumonía, $180(8,9 \%)$ con sepsis y $80(3,9 \%)$ con otras patologías invasoras. En el cuadro 2 se encuentra la distribución por grupos de edad y diagnóstico, en el cual se observa que en los niños menores de seis años se presentó con mayor frecuencia la meningitis $(46,8 \%)$ que en los mayores de 14 años $(38,1 \%)(p=0,0003)$, a diferencia de la neumonía que fue menos frecuente en los niños menores de 6 años $(40,3 \%)$ que en los mayores de 14 años $(48,8 \%)(p=$ 0,0003).

Se analizó el grupo de seis meses y se comparó con el de siete meses a dos años y con el de tres a seis años y se encontró una diferencia significativa en la frecuencia de meningitis $(64,9 \%$, $38,0 \%$ y $46,8 \%)(p<0,001)$ y de neumonía $(23,9 \%$, $48,6 \%$ y $51,5 \%)(p<0,001)$. En los adultos no se encontró diferencia significativa al comparar la frecuencia de neumonía entre los $>14$ años $y \geq 50$ años ( $p=0,4$ y $p=0,5$, respectivamente).

\section{Tipos capsulares}

Se identificaron $56(62,2 \%)$ de los 90 tipos capsulares de $S$. pneumoniae descritos. Los nueve serotipos más importantes en los niños menores de seis años durante el tiempo de vigilancia fueron el $14(29,7 \%), 6 \mathrm{~B}(10,3 \%), 23 \mathrm{~F}(9,4 \%), 1$ (8\%), 5 (7\%), 6A (6,3\%), 19F (5,4\%), 18C (4,9\%) y $9 \mathrm{~V}$ $(2,6 \%)$, los cuales corresponden al $83,6 \%$. Para el grupo de los niños de 6 a 14 años, estos mismos

Cuadro 2. Distribución de los aislamientos de Streptococcus pneumoniae por grupos de edad y fuente del aislamiento, 1994-2004.

\begin{tabular}{cc}
\hline \multirow{2}{*}{ Enfermedad } & \multicolumn{3}{c}{ Grupos de edad en años } \\
\cline { 2 - 3 } & \multicolumn{2}{c|}{$6-14 \quad>14$} & Total \\
\cline { 2 - 3 } & \multicolumn{2}{c}{$\mathrm{n}(\%)$} &
\end{tabular}

Meningitis $558(46,8)^{*} 108(50,9) 235(38,1) \quad 901(44,6)$ Neumonía $480(40,3) \quad 80(37,8) \quad 301(48,8)^{\star} \quad 861(42,6)$

$\begin{array}{lllllllll}\text { Sepsis } & 100 & (8,4) & 16 & (7,5) & 64 & (10,4) & 180 & (8,9)\end{array}$

$\begin{array}{lllllllll}\text { Otras } & 55 & (4,5) & 8 & (3,8) & 17 & (2,7) & 80 & (3,9)\end{array}$

\begin{tabular}{lllll} 
Total & 1193 & 212 & 617 & 2022 \\
\hline
\end{tabular}

${ }^{{ }^{*}} p=0,0003$ nueve serotipos representaron el $74,0 \%$ y en los $>14$ años el $61,4 \%(p<0,001)$. La distribución de los serotipos en cada uno de los grupos de edad fue diferente. Como se observa en la figura 1, el serotipo 14 fue el más frecuente en los menores de seis años, con el $29,7 \%$, pero su frecuencia disminuyó en los otros grupos de edad a 12,7\% y $12,4 \%$, respectivamente.

En los niños menores de seis años, la distribución de los serotipos por procedencia mostró algunas diferencias significativas cuando se compararon los departamentos con Bogotá; el serotipo 14 fue más frecuente en Bogotá $(35,8 \%)$ y menos en Antioquia (20,2\%), Valle $(25,8 \%)$, Santander $(22,6 \%)$ y Risaralda $(20,4 \%)(p<0,05)$; el serotipo 6B fue más frecuente en Santander $(19,4 \%)(p=$ $0,02)$; el serotipo 23F fue más frecuente en Antioquia $(12,2 \%)$ y Valle $(13,9 \%)(p<0,01)$; el serotipo 5 fue más frecuente en el Valle $(13,2 \%)$ $(p=0,0006)$ y Risaralda $(14,3 \%)(p=0,02)$; en Santander no se presentó ningún aislamiento de este serotipo; el serotipo $18 \mathrm{C}$ fue más frecuente en Santander $(9,7 \%)(p=0,03)$. Los nueve principales serotipos representaron entre el $80 \mathrm{y}$ el $84,4 \%$ del total de aislamientos en estos sitios del país, lo cual no mostró diferencia significativa.

Durante los años de vigilancia se han presentado cambios en la frecuencia de los nueve principales serotipos de aislamientos invasores de $S$. pneumoniae en los menores de seis años; el serotipo 14 se ha incrementado en forma significativa $(p<0,0001)$ y han disminuido los serotipos 5 y $19 \mathrm{~F}(p=0,05$ y $p=0,02$, respectivamente) (cuadro 3 ). En los otros grupos de edad no se han observado cambios significativos.

Al analizar la frecuencia de los serotipos por subgrupos de edad, se encontró que en los menores de dos meses $(n=80)$ la distribución fue diferente. El serotipo más importante fue el 5 $(30 \%)$, seguido del $7 \mathrm{~F}(10 \%), 1(8,8 \%)$ y el 14 $(7,5 \%)$, a diferencia de los niños entre dos y seis meses $(n=333)$, cuya distribución fue similar al grupo de menores de seis años. En cuanto a los adultos, en el grupo de edad de 15 a 50 años los serotipos más frecuentes fueron 1 (13,2\%), 14 $(11,3 \%), 5(8,2 \%)$ y $23 \mathrm{~F}(5,3 \%)$; en los de 51 a 65 

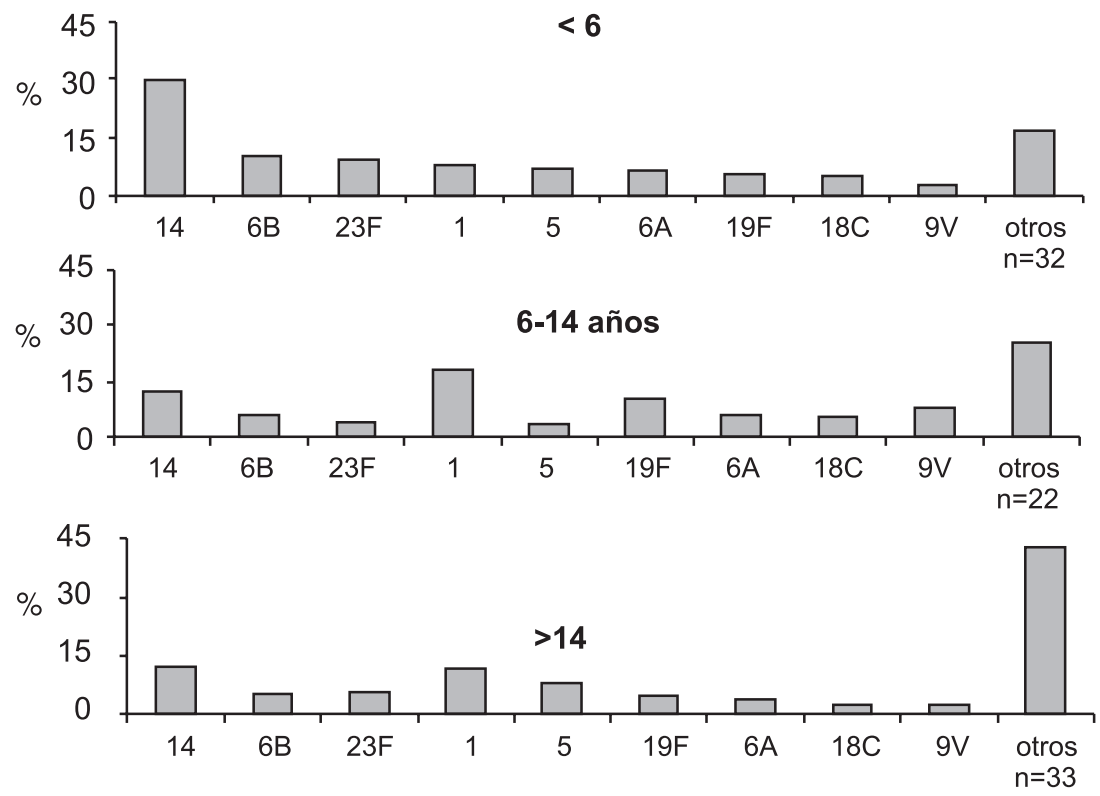

Serotipos

Figura 1. Distribución de los serotipos de Streptococcus pneumoniae por grupos de edad, 1994-2004.

Cuadro 3. Evolución de los serotipos de los aislamientos invasores de Streptococcus pneumoniae recuperados de niños menores de 6 años durante la vigilancia, 1994-2004.

\begin{tabular}{|c|c|c|c|c|c|c|c|c|c|c|c|c|}
\hline \multirow{3}{*}{$\begin{array}{l}\text { Serotipo } \\
14\end{array}$} & \multicolumn{10}{|c|}{ Años de vigilancia } & \multirow{2}{*}{\multicolumn{2}{|c|}{ Total }} \\
\hline & \multicolumn{2}{|c|}{$94-95$} & \multicolumn{2}{|c|}{$96-97$} & \multicolumn{2}{|c|}{$98-99$} & \multicolumn{2}{|c|}{$00-01$} & \multicolumn{2}{|c|}{$02-04$} & & \\
\hline & 65 & $(21,2)$ & 56 & $(28,3)$ & 63 & $(38,6)$ & 63 & $(31,5)$ & 108 & $(33,2)$ & 355 & $(29,7)$ \\
\hline $6 \mathrm{~B}$ & 27 & $(8,8)$ & 24 & $(12,1)$ & 15 & $(9,2)$ & 25 & $(12,5)$ & 32 & $(9,8)$ & 123 & $(10,3)$ \\
\hline $23 \mathrm{~F}$ & 30 & $(9,8)$ & 27 & $(13,6)$ & 13 & $(8,0)$ & 20 & $(10,0)$ & 22 & $(6,8)$ & 112 & $(9,4)$ \\
\hline 1 & 28 & $(9,1)$ & 6 & $(3,0)$ & 13 & $(8,0)$ & 18 & $(9,0)$ & 30 & $(9,2)$ & 95 & $(8,0)$ \\
\hline 5 & 33 & $(10,7)$ & 13 & $(6,6)$ & 4 & $(2,4)$ & 14 & $(7,0)$ & 19 & $(5,8)$ & 83 & $(7,0)$ \\
\hline $6 \mathrm{~A}$ & 18 & $(5,9)$ & 10 & $(5,1)$ & 12 & $(7,4)$ & 10 & $(5,0)$ & 25 & $(7,7)$ & 75 & $(6,3)$ \\
\hline $19 \mathrm{~F}$ & 21 & $(6,8)$ & 16 & $(8,1)$ & 12 & $(7,4)$ & 5 & $(2,5)$ & 10 & $(3,1)$ & 64 & $(5,4)$ \\
\hline $18 \mathrm{C}$ & 15 & $(4,9)$ & 9 & $(4,5)$ & 8 & $(4,9)$ & 6 & $(3,0)$ & 20 & $(6,2)$ & 58 & $(4,9)$ \\
\hline $9 \mathrm{~V}$ & 5 & $(1,6)$ & 5 & $(2,5)$ & 2 & $(1,2)$ & 9 & $(4,5)$ & 10 & $(3,1)$ & 31 & $(2,6)$ \\
\hline otros & 65 & $(21,2)$ & 32 & $(16,2)$ & 21 & $(12,9)$ & 30 & $(15,0)$ & 49 & $(15,1)$ & 197 & $(16,4)$ \\
\hline Total & 307 & & 198 & & 163 & & 200 & & 325 & & 1193 & \\
\hline
\end{tabular}

fueron el $14(13,9 \%), 1(11,1 \%), 23 F(10,2 \%)$ y 3 $(10,2 \%)$, y en el de mayores de 65 , los serotipos $14(13,2 \%), 3(13,2 \%), 6 B(9,3 \%)$ y $1(8,5 \%)$.

Los serotipos asociados con meningitis para el grupo de los menores de seis años fueron el 14 $(25,3 \%), 23 \mathrm{~F}(12,2 \%), 6 \mathrm{~B}(10 \%), 19 \mathrm{~F}(7 \%), 6 \mathrm{~A}$ $(6,8 \%)$ y $18 \mathrm{C}(6,8 \%)$; los asociados con neumonía fueron el $14(39,6 \%), 1(13,3 \%), 6 \mathrm{~B}(9,8 \%), 5(8,1 \%)$ y el $23 \mathrm{~F}(7,1 \%)$. El análisis de los subgrupos de distribución de los serotipos por enfermedad mostró que en los menores de dos meses el serotipo más importante como agente de meningitis fue el 5 (35,4\%), seguido del $7 \mathrm{~F}(14,6 \%)$ y del 1 (8,3\%); para neumonía, los más importantes fueron el $5(23,5 \%)$, el $14(17,6 \%)$, $6 \mathrm{~A}(17,6)$ y el $1(11,8 \%)$, a diferencia de los niños entre dos y seis meses, cuya distribución fue similar a la del grupo de menores de seis años. En los adultos mayores de 64 años se encontró 
que en la meningitis los serotipos más importantes fueron el $19 \mathrm{~F}(17,9 \%), 3(14,3 \%), 23 \mathrm{~F}(10,7 \%)$, $14(10,7 \%)$ y $6 \mathrm{~B}(10,7 \%)$ y en la neumonía, los serotipos $14(19,3 \%), 3(10,2 \%), 6 \mathrm{~B}(9,1 \%), 1$ $(9,1 \%)$ y $5(8,0 \%)$.

\section{Susceptibilidad antimicrobiana}

Del total de aislamientos estudiados, 602 (29,8\%) presentaron susceptibilidad disminuida a la penicilina (SDP) (resistencia intermedia y alta), $896(44,3 \%)$ a SXT, $655(32,4 \%)$ a tetraciclina, $166(8,2 \%)$ a cloranfenicol y $77(3,8 \%)$ a eritromicina; la resistencia a ceftriaxona se presentó en $2 / 861(0,2 \%)$ de los aislamientos de pacientes con neumonía y en 41/1161 (3,5\%) con otras enfermedades; todos los aislamientos fueron sensibles a vancomicina. En el cuadro 4 se registra el comportamiento de los aislamientos frente a los antibióticos estudiados por grupos de edad y se observa que la resistencia global a penicilina, ceftriaxona, SXT y tetraciclina es más alta en los menores de seis años que en el resto de la población $(p<0,01)$. Con el cloranfenicol y la eritromicina el comportamiento fue similar en los diferentes grupos de edad. La prueba de sensibilidad a las fluoroquinolonas de 269 aislamientos de pacientes con neumonía mayores de 14 años indicó que 4 (1,5\%) fueron resistentes a levofloxacina mediante la técnica de difusión de disco, y $43(16,7 \%)$ tenían una $\mathrm{CIM}=4,0 \mu \mathrm{g} /$ $\mathrm{ml}$ a ciprofloxacina.

En el análisis de la SDP de los aislamientos de S. pneumoniae por procedencia, Bogotá presentó una resistencia del $34,4 \%$ (7,5\% de intermedia y $26,9 \%$ de alta resistencia), Antioquia $29,6 \%$ (14,8\% intermedia y $14,8 \%$ alta), Valle $23,2 \%$ (13,5\% intermedia y $9,7 \%$ alta), Risaralda $23,9 \%$ (16,8\% intermedia y $7,1 \%$ alta) y Santander $21 \%$ (12,0\% intermedia y $9,0 \%$ alta). Para Bogotá, la frecuencia de aislamientos con SDP fue mayor que en el Valle, Risaralda y Santander $(p<0,01)$, con un mayor número de aislamientos con alta resistencia a penicilina que en los otros cuatro sitios analizados $(p<0,01)$.

Al analizar la evolución de la SDP por grupos de edad se observó que en los menores de seis años, la SDP pasó de 10\% (6,4\% de intermedia y $3,6 \%$ de alta resistencia) en 1994 a 37,7\% (10,5\% intermedia y $27,2 \%$ alta) en el 2004 , presentándose el mayor incremento en el 2001 con un $55,7 \%$ (14,4\% intermedia y $41,3 \%$ alta). En el grupo de 6 a 14 años osciló entre 21,4\% (7,1\% intermedia y $14,3 \%$ alta) y $26,5 \%(5,9 \%$ intermedia y $20,6 \%$ alta) y en los adultos se mantuvo constante entre $24,4 \% \quad(10,3 \%$

Cuadro 4. Susceptibilidad antimicrobiana de los aislamientos invasores de Streptococcus pneumoniae por grupos de edad, 1994-2004.

\begin{tabular}{|c|c|c|c|c|c|c|c|c|c|}
\hline \multirow{3}{*}{ Antibiótico } & \multicolumn{9}{|c|}{ Grupo de edad } \\
\hline & \multicolumn{3}{|c|}{$\begin{array}{l}<6 \text { años } \\
n=1.193\end{array}$} & \multicolumn{3}{|c|}{$\begin{array}{c}6 \text { - } 14 \text { años } \\
n=212 \\
\text { Interpretación } \\
n(\%)\end{array}$} & \multicolumn{3}{|c|}{$\begin{array}{c}>15 \text { años } \\
n=617\end{array}$} \\
\hline & $\mathrm{S}$ & I & $\mathbf{R}$ & $\mathrm{S}$ & I & $\mathbf{R}$ & $\mathrm{S}$ & I & $\mathbf{R}$ \\
\hline Penicilina & $788(66,1)$ & $151(12,7)$ & $254(21,2)$ & $161(75,9)$ & $18(8,5)$ & $33(15,6)$ & $471(76,3)$ & $59(9,6)$ & $87(14,1)$ \\
\hline Ceftriaxona* & $593(83,2)$ & $90(12,6)$ & $30(4,2)$ & $113(85,6)$ & $16(12,1)$ & $3(2,3)$ & $276(87,4)$ & $32(10,0)$ & $8(2,6)$ \\
\hline Ceftriaxona** & $438(91,3)$ & $40 \quad(8,3)$ & $2(0,4)$ & $79(98,7)$ & $1(1,3)$ & & $292(97,0)$ & $9(3,0)$ & \\
\hline $\mathrm{SXT}$ & $615(51,6)$ & $183(15,3)$ & $395(33,1)$ & $134(63,2)$ & $26(12,3)$ & $52(24,5)$ & $377(61,1)$ & $85(13,8)$ & $155(25,1)$ \\
\hline Cloranfenicol & $1085(90,9)$ & & $108(9,1)$ & $205(96,7)$ & & $7 \quad(3,3)$ & $566(91,7)$ & & $51(8,3)$ \\
\hline Eritromicina & $1141(95,6)$ & $18(1,5)$ & $34(2,9)$ & $209(98,6)$ & & $3(1,4)$ & $595(96,4)$ & & $22(3,6)$ \\
\hline Tetraciclina & $755(63,3)$ & $24(2,0)$ & $414(34,7)$ & $161(75,8)$ & $5(2,4)$ & $46(21,8)$ & $438(71,0)$ & $18(2,9)$ & $161(26,1)$ \\
\hline \multicolumn{10}{|c|}{$\begin{array}{l}\text { (23) }(n=1.161) \\
\text { * Aislamientos de pacientes con enfermedad diferente a neumonía de acuerdo con las recomendaciones de la NCCLS }\end{array}$} \\
\hline
\end{tabular}


Cuadro 5. Evolución de la susceptibilidad antimicrobiana a la penicilina de los aislamientos invasores de Streptococcus pneumoniae en niños menores de 6 años de acuerdo con la concentración inhibitoria mínima en $\mu \mathrm{g} / \mathrm{ml}, 1994-2004$.

\begin{tabular}{|c|c|c|c|c|c|c|c|c|c|c|c|c|c|}
\hline & & \multicolumn{10}{|c|}{ Períodos de vigilancia } & & \\
\hline \multicolumn{2}{|c|}{$\begin{array}{l}\text { Concentración } \\
\text { inhibitoria } \\
\text { mínima }\end{array}$} & \multicolumn{2}{|c|}{$\begin{array}{c}1994-1995 \\
n=307\end{array}$} & \multicolumn{2}{|c|}{$\begin{array}{c}1996-1997 \\
n=198\end{array}$} & \multicolumn{2}{|c|}{$\begin{array}{c}1998-1999 \\
n=163\end{array}$} & \multicolumn{2}{|c|}{$\begin{array}{c}2000-2001 \\
n=200\end{array}$} & \multicolumn{2}{|c|}{$\begin{array}{c}2002-2004 \\
n=325\end{array}$} & \multicolumn{2}{|c|}{$\begin{array}{c}\text { Total } \\
\mathrm{n}=1193\end{array}$} \\
\hline$(\mu \mathrm{g} / \mathrm{ml})$ & $I^{*}$ & \multicolumn{12}{|c|}{ n (\%) } \\
\hline 0,03 & $\mathrm{~S}$ & 257 & $(83,7)$ & 92 & $(46,5)$ & 76 & $(46,6)$ & 92 & $(46,0)$ & 155 & $(47,7)$ & 672 & $(56,3)$ \\
\hline 0,06 & $S$ & 13 & $(4,2)$ & 44 & $(22,2)$ & 12 & $(7,4)$ & 15 & $(7,5)$ & 30 & $(9,2)$ & 114 & $(9,6)$ \\
\hline 0,125 & I & 9 & $(2,9)$ & 8 & $(4,0)$ & 13 & $(8,0)$ & 3 & $(1,5)$ & 12 & $(3,7)$ & 45 & $(3,8)$ \\
\hline 0,25 & I & 11 & $(3,6)$ & 10 & $(5,0)$ & 4 & $(2,5)$ & 14 & $(7,0)$ & 10 & $(3,1)$ & 49 & $(4,1)$ \\
\hline 0,5 & I & 5 & $(1,6)$ & 14 & $(7,1)$ & 1 & $(0,6)$ & 2 & $(1,0)$ & 6 & $(1,8)$ & 28 & $(2,3)$ \\
\hline 1 & I & 2 & $(0,7)$ & 11 & $(5,6)$ & 2 & $(1,2)$ & 6 & $(3,0)$ & 10 & $(3,1)$ & 31 & $(2,6)$ \\
\hline $1^{* *}$ & I & 1 & & 3 & & 2 & & 4 & & 5 & & 15 & \\
\hline 2 & $\mathrm{R}$ & 8 & $(2,6)$ & 8 & $(4,0)$ & 38 & $(23,3)$ & 51 & $(25,5)$ & 95 & $(29,2)$ & 200 & $(16,8)$ \\
\hline $2^{* *}$ & $\mathrm{R}$ & 5 & & 6 & & 23 & & 29 & & 42 & & 105 & \\
\hline 4 & $\mathrm{R}$ & 2 & $(0,7)$ & 11 & $(5,6)$ & 17 & $(10,4)$ & 17 & $(8,5)$ & 7 & $(2,2)$ & 54 & $(4,5)$ \\
\hline $4^{\star *}$ & $\mathrm{R}$ & 2 & & 7 & & 10 & & 9 & & 1 & & 29 & \\
\hline
\end{tabular}

* Interpretación por la NCCLS

** Aislamientos de pacientes con neumonía

$\mathrm{S}=$ sensible $(\leq 0,06 \mu \mathrm{g} / \mathrm{ml})$

$\mathrm{I}=$ intermedio $(0,125-1,0 \mu \mathrm{g} / \mathrm{ml})$

$\mathrm{R}=$ resistente $(\leq 2,0 \mu \mathrm{g} / \mathrm{ml})$

intermedia y $14,1 \%$ alta) y $25 \%(8,3 \%$ intermedia y $16,7 \%$ alta). En el cuadro 5 se evidencia la evolución de la CIM de los aislamientos en menores de seis años y se muestra el incremento significativo $(p<0,01)$ de los aislamientos con una CIM de 2,0 $\mu \mathrm{g} / \mathrm{ml}$, así como la disminución de los aislamientos con una $\mathrm{CIM} \leq 0,03 \mu \mathrm{g} / \mathrm{ml}$, pero no se observaron cambios significativos en la frecuencia de los aislamientos con susceptibilidad intermedia a la penicilina $(0,06 \mu \mathrm{g} /$ $\mathrm{ml} \mathrm{a} 1,0 \mu \mathrm{g} / \mathrm{ml}$ ).

En los menores de seis años, el 31,6\% (16,7\% de intermedia y $14,9 \%$ de alta resistencia) de los aislamientos de pacientes con meningitis tenían SDP y el $37,5 \%(9,6 \%$ intermedia y $27,9 \%$ alta $)$ de los pacientes con neumonía; en el grupo de 6 a 14 años fue de $24,1 \%$ (10,2\% intermedia y $13,9 \%$ alta) y de $22,6 \%$ (6,3\% intermedia y $16,3 \%$ alta), y en los mayores de 14 años fue $18,7 \%$ (8,9\% intermedia y $9,8 \%$ alta) y de $26,2 \%(10,6 \%$ intermedia y $15,6 \%$ alta), respectivamente. Se encontraron diferencias significativas tanto en la frecuencia de $\operatorname{SDP}(p=0,04)$ como en las de alta resistencia en los niños y en los adultos $(p<0,01$, $p=0,04)$. Al analizar los datos de los adultos en tres grupos de edad, 15 a 50, 51 a 65 y mayores de 65 , no se observaron diferencias significativas $(p=0,13)$

Los serotipos 14 (55,4\%), 23F (18,9\%), 6B (9,6\%), $9 \mathrm{~V}(6,0 \%)$ y $19 \mathrm{~F}(4,1 \%)$ representaron el $94 \%(566 /$ 603 ) de los aislamientos con SDP. Al analizar la frecuencia de SDP de estos serotipos con relación al número de aislamientos de cada uno se encontró que del serotipo 14, 334/457 (86\%) tenían SDP (intermedia $26,9 \%$ y alta $59,1 \%$ ), del $23 \mathrm{~F}$, $113 / 158(71,5 \%)$ (intermedia $53,8 \%$ y alta $17,7 \%$ ), $6 \mathrm{~B}, 58 / 170(34,1 \%)$ (intermedia $12,4 \%$ y alta $21,8 \%), 9 \mathrm{~V} 36 / 66$ (54,5\%) (intermedia $6,1 \%$ y alta $48,5 \%$ ) y $19 \mathrm{~F} 25 / 115(21,7 \%$ ) (intermedia $19,1 \%$ y alta $2,6 \%$ ). Al analizar la SDP por serotipo y grupo de edad se observó sólo diferencia significativa en el serotipo 14 en los menores de seis años, $241 / 355(67,9 \%)$ presentaban SDP, mientras que en los adultos 70/75 $(93,3 \%)(p<0,01)$.

La multirresistencia, definida como la resistencia a tres o más clases de antibióticos, se presentó en el $14,5 \%$ de los aislamientos de niños menores de seis años y en el $11,5 \%$ del resto de la población. En los 264 aislamientos multirresistentes, el patrón más frecuente fue la resistencia a penicilina, SXT y tetraciclina, en 173 
$(65,5 \%)$ de los cuales 12 tenían además resistencia a eritromicina, 34 a cloranfenicol y 20 a eritromicina y cloranfenicol; el otro patrón importante fue la resistencia a SXT, cloranfenicol y tetraciclina en $65(24,6 \%)$ aislamientos, de los cuales el $95 \%$ eran serotipo 5 . De los 264 aislamientos multirresistentes, $20(7,6 \%)$ eran resistentes a cinco antibióticos y $48(18,2 \%)$ a cuatro.

Al analizar la multirresistencia en cada uno de los serotipos se encontró que $64 / 138$ (46,4\%) de los aislamientos serotipo 5 eran multirresistentes, 68/ $158(43 \%)$ del serotipo 23F, 51/170 (30\%) del serotipo 6B y 53/457 (11,6\%) del serotipo 14 .

\section{Tipificación molecular}

Con la técnica de electroforesis en campo pulsado, y teniendo en cuenta la distribución por serotipos, durante el periodo de vigilancia se tipificaron 602 aislamientos con SDP y 126 aislamientos tipo capsular 5. Los aislamientos con SDP se agruparon en 102 patrones electroforéticos. El $73 \%$ de los aislamientos se agrupó en cuatro patrones designados como A $(4,4 \%)$, B (50\%), C (12,5\%) y D $(6,1 \%)$.

Los principales hallazgos de la tipificación molecular se describen teniendo en cuenta su distribución por serotipos. De los 113 aislamientos con tipo capsular 23F, 27 (23,9\%) fueron multirresistentes y conformaron el patrón $A$, relacionado por fenotipo y genotipo con el clon 1España $^{23 F}$. Además, 73 (64,6\%) aislamientos del mismo serotipo presentaron resistencia intermedia a la penicilina y variable a SXT y tetraciclina $y$, junto a un aislamiento con serotipo $19 \mathrm{~F}$ y otro con serotipo 34, integraron el patrón C, relacionados todos con el clon 26 -Colombia ${ }^{23 F}$. Los 13 aislamientos restantes presentaron diferentes patrones electroforéticos y no se asociaron con clones internacionales.

Los serotipos $14(n=334)$ y $9 V(n=36)$ se analizaron conjuntamente, debido a que entre estos serotipos es frecuente el intercambio de genes capsulares por medio de transformación genética. Un total de 279 (83,5\%) aislamientos con serotipo 14 y 22 (61\%) del 9V conformaron el patrón $\mathrm{B}$ y se encontraron relacionados fenotípica y genotípicamente con el clon 3-España ${ }^{9 v}$. Los patrones de PFGE de los 69 aislamientos restantes no se relacionaron con los clones internacionales descritos hasta el momento.

De los 58 aislamientos con serotipo 6B, 38 $(65,5 \%)$ integraron el patrón $D$ con fenotipo multirresistente y relacionado con el clon 2$E_{\text {spaña }}{ }^{6 \mathrm{~B}}$. Los otros 20 presentaron diversos patrones de PFGE. Los 59 aislamientos de los otros 20 serotipos se distribuyeron en 40 patrones electroforéticos no relacionados con ningún clon. Los 138 aislamientos serotipo 5 se relacionaron genéticamente con el clon 19-Colombia ${ }^{5}$, el cual fenotípicamente es resistente a trimetoprimsulfametoxazol, a cloranfenicol y a tetraciclina.

Se obtuvieron 36 perfiles de restricción, identificados por los números romanos de I a XXXVI. Los 19 aislamientos agrupados electroforéticamente con el clon 1 y los 13 relacionados con el clon 3 presentaron el perfil de restricción pbp I; en los 64 restantes del clon 3 se observó el perfil pbp III; los 34 aislamientos del clon 26 presentaron el perfil pbp II y los 12 aislamientos del clon 2 exhibieron diversos perfiles de $p b p$ (VI,VII, XXIII). Los 111 aislamientos restantes se agruparon en 19 perfiles $p b p$ diferentes.

\section{Cobertura teórica de las diferentes vacunas conjugadas}

De acuerdo con la frecuencia de los serotipos en los menores de seis años, la cobertura teórica de la vacuna heptavalente (serotipos $4,6 \mathrm{~B}, 9 \mathrm{~V}, 14$, $18 \mathrm{C}, 19 \mathrm{~F}$ y $23 \mathrm{~F}$ ) sería del $64,1 \%$, en general; para meningitis, $64,7 \%$ y para neumonía, $63,2 \%$. Al analizar la cobertura en los niños de cero a seis meses, se encontró que la cobertura teórica general sería de $57,8 \%$, para meningitis, $57,8 \%$ y para neumonía, $62,5 \%$. Con la vacuna de 10 serotipos, que incluye los serotipos 1,5 y $7 \mathrm{~F}$, la cobertura general para los menores de seis años sería de $80,8 \%$ y para los de cero a seis meses de $78,1 \%$, y con la vacuna de 13 serotipos, que adicionalmente tiene los serotipos 3, 6A y 19A, sería del $89,3 \%$ y $87,3 \%$, respectivamente.

$\mathrm{Al}$ analizar la cobertura de las vacunas contra los serotipos con SDP, se encontró que para los 
menores de seis años sería del $96,3 \%$ con la heptavalente y la de 10 serotipos y del $98 \%$ con la de 13 serotipos.

\section{Discusión}

La vigilancia por laboratorio de los serotipos y de la susceptibilidad antimicrobiana de $S$. pneumoniae en Colombia ha permitido establecer los serotipos prevalentes, los patrones de resistencia a los antibióticos y determinar las relaciones clonales de los aislamientos invasores de S. pneumoniae, cumpliendo así con su objetivo principal, cual es el de proporcionar información adicional al sistema general de vigilancia en salud pública para la implementación de medidas de control y prevención de la infección neumocócica (19).

Sin embargo, presenta varias limitantes, como son la falta de recursos económicos del sistema general de salud y del apoyo a los LSP para realizar programas de vigilancia por el laboratorio, lo que hace que la mayoría de los aislamientos de $S$. pneumoniae $(79,2 \%)$ procedan de tres regiones del país que representan aproximadamente el $40 \%$ de la población colombiana. La baja cobertura se presenta a pesar de que, de acuerdo con la ley 715 , la vigilancia por el laboratorio de estos patógenos de impacto en salud pública es obligatoria y que desde el año 2004 lo es también la notificación de los casos de meningitis por $S$. pneumoniae al SIVIGILA. Además, se debe tener en cuenta que los datos de neumonía de esta vigilancia son de la clasificada como grave, debido a que es la que requiere hospitalización del paciente y causa la mayor morbimortalidad, pero sí son representativos de las meningitis, debido a que todas ellas, en especial en la población infantil, se estudian en el laboratorio y, en la mayoría de los casos, se aísla el patógeno.

Las fortalezas de estos datos las constituyen el programa de control de calidad de las metodologías utilizadas, el número de los aislamientos estudiados, que se ha mantenido en 100 por año, y el incremento en el número de hospitales que participan en el programa. Es así como en la actualidad participan 23 departamentos y el Distrito Capital, con un total de 120 hospitales. Además, todos los aislamientos proceden de líquidos normalmente estériles y cuentan con el dato de la edad del paciente y de la fuente del aislamiento, de tal forma que la información obtenida de los serotipos será una herramienta que permita medir el impacto de la vacuna cuando ésta sea integrada a la vacunación regular de la población infantil en Colombia, como sucedió con la vacuna de Haemophilus influenzae (20).

Durante los primeros años de la vigilancia se observó que cerca del $90 \%$ de los aislamientos eran de niños menores de seis años. Esto se debe a que el proyecto SIREVA estaba diseñado para el estudio de los serotipos y de la resistencia a los antibióticos de $S$. pneumoniae recuperados en este grupo de edad (8). Al integrarse el proyecto SIREVA con la vigilancia por laboratorio a través de los programas de IRA y MBA, la distribución de los aislamientos según el grupo de edad se modificó y en la actualidad cerca del $40 \%$ son de adultos.

La neumonía y la meningitis fueron los diagnósticos más frecuentes en niños menores de seis años, similar a lo publicado en varios países de Latinoamérica (9), pero diferente a lo informado en algunos países europeos $(21,22)$ y Estados Unidos (23) donde la principal causa de diagnóstico de infección por $S$. pneumoniae es la bacteriemia. Lagos y colaboradores, en un estudio piloto realizado en Chile, establecieron que se presenta aproximadamente un caso de bacteriemia oculta en niños de edad igual o menor a 36 meses que acuden con fiebre alta a las salas de urgencias por cada caso de hospitalización por enfermedad neumocócica. De acuerdo con estos datos, la incidencia de la enfermedad invasiva por S. pneumoniae podría estar subestimada (24).

Se observó que los niños de cero a seis meses son más vulnerables a sufrir meningitis que neumonía, acorde con informes previos que muestran que la incidencia de meningitis es mayor en los niños de menor edad. En un estudio prospectivo realizado por Casado Flores y colaboradores en España, se encontró que la incidencia de meningitis fue de 17,7/100.000 en niños menores de un año y disminuyó a 8,4/ 100.000 en niños en el segundo año de vida (25). 
Además, los niños menores de seis meses tienen un mayor riesgo de daños neurológicos y de muerte (26).

Fueron relativamente pocos los serotipos de $S$. pneumoniae más frecuentemente asociados con enfermedad invasiva en todos los grupos de edad; sin embargo, se observaron diferencias en su prevalencia durante el periodo de vigilancia y en su distribución por edad. En los menores de seis años se observó un incremento significativo en el serotipo $14(p=0,04)$ con respecto al análisis de 1993-1999 (8), pero en los serotipos 5 y 23F se observó una disminución, aunque no significativa. El serotipo 14 es el más prevalente en los menores de seis años no sólo en Colombia sino en otros países latinoamericanos como Brasil, Argentina, Chile y Uruguay (8), así como en Estados Unidos antes de la vacuna heptavalente (23), y es recuperado con menor frecuencia en países como México (8), España (21) y los países asiáticos (11). Se observaron diferencias por regiones en la frecuencia de los serotipos al compararlas con Bogotá, aunque los nueve serotipos más frecuentes fueron los mismos en los sitios analizados.

S. pneumoniae serotipo 14 se recuperó en mayor proporción en el grupo de los niños menores de seis años y su frecuencia decreció a medida que se incrementó la edad, a diferencia de lo observado con el serotipo 1 , que fue más frecuente en los grupos de niños mayores y adultos, con 18,4 y $11,8 \%$, respectivamente. Estas diferencias en la distribución por edad son comparables con las descritas en otros trabajos de vigilancia epidemiológica $(27,28)$.

Es interesante el incremento del tipo capsular 3 con respecto a la edad, que pasa de $1,3 \%$ en los menores de seis años a 3,3\% en los de 6 a 14 años y a $12,1 \%$ en los mayores de 65 años, similar a lo descrito en España y Estados Unidos $(21,23)$. En el grupo de mayores de 65 años, este serotipo es el segundo en importancia tanto en meningitis como en neumonía, datos éstos similares a los informados en Brasil por Brandileone y col (27) quienes encontraron que en los adultos mayores de 50 años era el más importante en la meningitis $(20,3 \%)$ y el segundo en la neumonía $(11,1 \%)$. Estas diferencias en la distribución de ciertos serotipos según la edad se deben posiblemente a variaciones en la inmunidad o a diferencias antigénicas de los diferentes serotipos (28).

En los menores de seis años, el serotipo 5 es muy importante para los países latinoamericanos como Uruguay, Brasil y Chile $(8,27,28)$, donde ocupa el segundo o tercer lugar, y para Colombia, en donde ocupa el quinto lugar como sucede en España (21). En este estudio se encontró que en los departamentos del Valle y Risaralda, este serotipo ocupa el tercer lugar, y en los menores de dos meses es uno de los más importantes tanto para meningitis como para neumonía.

En niños menores de dos meses, la distribución de los serotipos cambió significativamente, recuperándose con mayor frecuencia $S$. pneumoniae de los tipos capsulares $5,7 \mathrm{~F}, 1$ y 14, de forma similar a lo informado en otros estudios $(2,29)$. Los serotipos 1,5 y $7 \mathrm{~F}$ tienen alto potencial para causar enfermedad invasiva, pero son poco frecuentes en portadores nasofaríngeos (2) y como causantes de enfermedad en niños no neonatos (2,29). La fuente de adquisición de estos serotipos en los neonatos no es clara, aunque existe la posibilidad de transmisión horizontal por adultos portadores; Gómez y colaboradores, encontraron evidencia de cultivos positivos para $S$. pneumoniae en 41 madres de 114 neonatos con infección neumocócica, lo que sugiere la transmisión vertical de la bacteria a partir de madres colonizadas o con infección invasora por S. pneumoniae (30).

El desarrollo de resistencia a uno o más antibióticos en aislamientos de $S$. pneumoniae y su posterior diseminación constituyen un problema importante para el tratamiento de las infecciones causadas por este microorganismo $(7,10)$. En general, los serotipos resistentes a los antibióticos en Colombia son los mismos reconocidos universalmente, pero con diferente prevalencia (31). Particular énfasis se le ha dado al estudio de la evolución de la resistencia a la penicilina, la cual, como ha ocurrido en muchas partes del mundo, se ha incrementado durante los años de vigilancia $(8,11,32)$.

Durante los primeros años de vigilancia se notó un aumento constante del número de aislamientos 
resistentes a la penicilina, alcanzado su máximo valor en el año 2001, para posteriormente descender y presentar tendencia a estabilizarse, de manera similar a la evolución del serotipo 14. Este comportamiento sigmoidal de la resistencia es muy similar al observado en los países con alta resistencia a la penicilina (33). Para el año 2004 , el $37,7 \%$ de los aislamientos presentaron resistencia a la penicilina, muy inferior a la informada para los países asiáticos (11), pero superior a la de la mayoría de los países europeos (33); este mismo comportamiento se observó con la resistencia a SXT (34). Estas diferencias en los niveles de resistencia reflejan la importancia de la presión selectiva de los antibióticos en la selección de fenotipos resistentes como consecuencia directa del consumo de antibióticos, la cual difiere ampliamente entre los países europeos, que tienen un programa de control de medicamentos (33), y países como el nuestro donde no se cuenta con políticas para el buen uso de los antimicrobianos.

La resistencia a ceftriaxona fue baja, especialmente en pacientes con neumonía $(0,2 \%)$, por lo que puede considerarse como una alternativa terapéutica en esta clase de infecciones debido a los buenos resultados obtenidos en el tratamiento de infecciones por S. pneumoniae que tienen CIM $<2 \mathrm{mg} / \mathrm{ml}$ (35). Los niveles de resistencia a eritromicina fueron bajos $(3,8 \%)$ y contrastan con muchos informes en los cuales se documentan altos niveles de resistencia a macrólidos $(11,36)$; sin embargo, es importante tener en cuenta que se ha evidenciado que en los países en donde existe un alto consumo de macrólidos se puede dar un rápido incremento de aislamientos resistentes a esta familia de antibióticos (31). De igual forma, la resistencia a levofloxacina es baja $(1,5 \%)$; esta fluoroquinolona de amplio espectro ha surgido como una alternativa terapéutica para la neumonía causada por $S$. pneumoniae en adultos; sin embargo, no se recomienda como primera opción, sino que debería reservarse para pacientes con infecciones causadas por aislamientos resistentes a otros antibióticos y pacientes alérgicos a B-lactámicos (37).

El $13 \%$ de los aislamientos presentaron multirresistencia asociada principalmente con penicilina y unos pocos serotipos, un hecho ampliamente documentado que demuestra la capacidad de la bacteria para adaptarse y sobrevivir a la presión selectiva ejercida por los antibióticos $(37,38)$, lo que se debe a que en $S$. pneumoniae la mayoría de los determinantes genéticos de resistencia están codificados en el cromosoma, son estables y se expresan constitutivamente, favoreciendo la dispersión de la bacteria en regiones con amplio consumo de antimicrobianos (38).

Desde su creación en 1997, la red de epidemiología molecular de neumococo (PMEN, del inglés Pneumococcal Molecular Epidemiology Network) ha reconocido 26 clones de $S$. pneumoniae resistentes al menos a un antibiótico de amplio uso clínico $(39,40)$. Los estudios de tipificación molecular han señalado la circulación en Colombia de los clones internacionales 1España $^{23 F}, 2-E_{\text {spaña }}{ }^{6 B}, 3-$ España $^{9 v}, 19-$ Colombia $^{5}$ y 26 -Colombia ${ }^{23 F}$, demostrando que, en parte, el incremento de la resistencia a los antibióticos en nuestro medio es consecuencia de la dispersión por transmisión de humano a humano de unos pocos grupos clonales que tienen determinantes genéticos de resistencia a antimicrobianos (8).

Los clones 1-España ${ }^{23 F}$, 2-España ${ }^{6 \mathrm{~B}}$, 3-España ${ }^{9 \mathrm{~V}}$ y 26 -Colombia ${ }^{23 F}$ agrupan el $73 \%$ de los aislamientos colombianos resistentes a la penicilina. Estos clones son resistentes a más de un antibiótico, tienen amplia dispersión mundial y su frecuencia cambia según las zonas geográficas (38). Así por ejemplo, el clon1España $^{23 F}$ es poco frecuente en nuestro país, pero es uno de los más prevalentes en los países asiáticos (11,41), México (42) y Estados Unidos (8). Los aislamientos de S. pneumoniae relacionados con el clon 3-España ${ }^{9 v}$ que expresan el tipo capsular 14 se recuperan con mayor frecuencia en Colombia, Uruguay (43), Argentina (44), Portugal (45) e Israel (46), a diferencia de lo informado en México (42) y en Estados Unidos (10) donde la mayoría los aislamientos son serotipo 9V. Sin embargo, hasta el momento no se tiene una explicación sobre el porqué de estas diferencias epidemiológicas regionales.

La vigilancia molecular de los aislamientos invasores de $S$. pneumoniae colombianos ha 
permitido la identificación de dos grupos clonales reconocidos por la PMEN; el clon 26-Colombia ${ }^{23 F}$ (16) exhibe resistencia intermedia a la penicilina y resistencia al cloranfenicol, y se ha informado también en Portugal (45), y el clon 19-Colombia ${ }^{5}$ (47) resistente a cloranfenicol y tetraciclina, notificado en países latinoamericanos (48) e Israel (46). El conocimiento de la distribución clonal de los aislamientos de $S$. pneumoniae permite determinar el mecanismo de dispersión, establecer la expansión clonal, detectar el surgimiento de nuevas líneas clonales, vigilar eventos genéticos que por transferencia horizontal de genes puedan generar cambios en el tipo capsular o la generación de variantes clonales con nuevos marcadores de resistencia (46).

La vacuna conjugada heptavalente contra $S$. pneumoniae (Prevenar, Wyeth-Lederle) se introdujo en el mercado colombiano en el 2001; sin embargo, su uso está restringido sólo a una parte de la población debido a sus altos costos (49). La composición de la vacuna se basó en los 7 serotipos más frecuentes en los Estados Unidos $(4,6 \mathrm{~B}, 9 \mathrm{~V}, 14,18 \mathrm{C}, 19 \mathrm{~F}$ y $23 \mathrm{~F})$ y ha demostrado reducir la tasa de enfermedad invasora en niños menores de 2 años en ese país (50). Teniendo en cuenta la frecuencia de los serotipos en menores de seis años, la cobertura teórica de la vacuna en nuestro medio sería del $64 \%$, muy similar a la de otros países suramericanos como Brasil (63\%) (51) y Uruguay (51\%) (52), debido a diferencias en la distribución regional de los serotipos; el serotipo 4 no es prevalente en Sur América, en contraste con los serotipos 1 y 5 que se aíslan con mayor frecuencia en pacientes con enfermedad invasora, razón por la cual las vacunas con 10 y 13 serotipos proporcionarían una mayor protección en estos países. Adicionalmente, esto resalta la importancia de los datos generados por los programas de vigilancia de S. pneumoniae en la toma de decisiones sobre medidas de intervención en salud pública.

La vacuna heptavalente ha demostrado ser efectiva para reducir los niveles de resistencia a los antibióticos $(50,53,54)$; un efecto similar se podría esperar en nuestro país debido a que los serotipos contenidos en la vacuna representan el $97,3 \%$ de los aislamientos con SDP. Sin embargo, como consecuencia de la vacunación se ha observado en los niños inmunizados una disminución en los serotipos vacunales con un incremento en la colonización por serotipos no contenidos en la vacuna, probablemente debido a un reemplazo de serotipos o al desenmascaramiento de poblaciones minoritarias de $S$. pneumoniae $(50,54)$. El significado clínico y las consecuencias de este incremento aún no son claras y, por lo tanto, es necesario evaluar el impacto de la vacuna en la distribución de los serotipos colonizantes de $S$. pneumoniae en la población infantil, debido a que el uso generalizado de la vacuna conjugada podría alterar su distribución y eventualmente la enfermedad invasora.

El programa de vigilancia de $S$. pneumoniae ha venido cumpliendo con los objetivos propuestos de generar información sobre los serotipos de los aislamientos relacionados con la enfermedad invasora, determinar los patrones de susceptibilidad a los antibióticos, detectar cambios temporales o geográficos y establecer e identificar las relaciones clonales entre los aislamientos. Programas con estas características son necesarios para conocer la realidad epidemiológica de nuestro país y, de esta manera, elaborar las mejores estrategias aplicables a los programas de prevención, proponer conductas sobre aspectos terapéuticos y evaluar la utilidad de las vacunas conjugadas antineumocócicas.

\section{Conflicto de intereses}

Los autores declaramos que no existe conflicto de interés.

\section{Financiación}

El programa de vigilancia por laboratorio de los aislamientos invasores de $S$. pneumoniae cuenta con la colaboración financiera del Instituto Nacional de Salud, los Laboratorios de Salud Pública del país, la Organización Panamericana de la Salud (OPS) de Washington y Colombia y la Agencia de Desarrollo Internacional Canadiense (CIDA).

\section{Referencias}

1. Musher DM. Infections caused by Streptococcus pneumoniae: clinical spectrum, pathogenesis, immunity and treatment. Clin Infect Dis 1992;14:801-7. 
2. Hausdorff WP, Feikin DR, Klugman KP. Epidemiological differences among pneumococcal serotypes. Lancet Infect Dis 2005;5:83-93.

3. Instituto Nacional de Salud. Comportamiento de la notificación. Inf Quinc Epidemiol Nac 2004;9:1-10.

4. Instituto Nacional de Salud. Comportamiento de la notificación (continuación). Inf Quinc Epidemiol Nac 2004;9:17-28.

5. Obaro S, Adegbola R. The pneumococcus: carriage, disease and conjugate vaccines. J Med Microbiol 2002;51:98-104.

6. Organización Mundial de la Salud. Estrategia mundial de la OMS para contener la resistencia a los antimicrobianos. Ginebra: OMS; 2001. WHO/CDC/ CRS/DRS/2001.2

7. Tenover FC. Development and spread of bacterial resistance to antimicrobial agents: an overview. Clin Infect Dis 2001;33(Suppl. 3):S108-15.

8. Di Fabio JL, Castañeda E, Agudelo Cl, De la Hoz F, Hortal M, Camou T, et al. Evolution of Streptococcus pneumoniae serotypes and penicillin susceptibility in Latin America, Sireva-Vigía Group, 1993-1999. PAHO Sireva-Vigia Study Group. Pan American Health Organization. Pediatr Infect Dis J 2001;20:959-67.

9. Fedman C. Clinical relevance of antimicrobial resistance in the management of pneumococcal community-acquired pneumonia. J Lab Clin Med 2004;143:269-83.

10. Richter SS, Heilmann KP, Coffman SL, Huynh HK, Brueggemann AB, Pfaller MA, et al. The molecular epidemiology of penicillin-resistant Streptococcus pneumoniae in the United States, 1994-2000 Clin Infect Dis 2002; 34:330-9.

11. Song JH, Jung SI, Ko KS, Kim NY, Son JS, Chang $\mathbf{H}$, et al. High prevalence of antimicrobial resistance among clinical Streptococcus pneumoniae isolates in Asia (ANSORP study). Antimicrob Agents Chemother 2004;48:2101-7.

12. Instituto Nacional de Salud. Datos de vigilancia epidemiológica. [Consultado: febrero 21 de 2006]. Disponible en http:// www.ins.gov.co/pdf_investiga/ microbiologia_spn_05.pdf.

13. Organización Panamericana de la Salud e Instituto Nacional de Salud Colombia. Programa de vigilancia de los serotipos y resistencia antimicrobiana de Streptococcus pneumoniae y Haemophilus influenzae. Manual de procedimientos del proyecto SIREVA II, p. 41 - 99. 2004. [Consultado: 30 de noviembre de 2005]. Disponible en: http://www.paho.org/Spanish/AD/THS/ EV/LABS-manual-vigilancia-serotipos.pdf

14. National Committee for Clinical Laboratory Standards. Disk diffusion. Supplemental tables. M100S14 (M2-A8). Wayne PA: National Committee for Clinical Laboratory Standards; 2003.
15. National Committee for Clinical Laboratory Standards. MIC testing. Supplemental tables. M100S14 (M7-A6). Wayne PA: National Committee for Clinical Laboratory Standards; 2003.

16. Vela MC, Fonseca N, Di Fabio JL, Castañeda E. Presence of international multiresistant clones of Streptococcus pneumoniae in Colombia. Microb Drug Resist 2001;7:153-64.

17. Tenover FC, Arbeit RD, Goering RV, Mickelsen PA, Murray BE, Persing $\mathrm{DH}$, et al. Interpreting chromosomal DNA restriction patterns produced by pulsed-field gel electrophoresis: criteria for bacterial isolate typing. J Clin Microbiol 1995;33:2233-9.

18. Dean AG, Dean JA, Columbier D, Burton AH, Brendel KA, Smith DC, et al. Epi Info versión 6.0: a word processing, data-base and statistics program for epidemiology on microcomputers. Atlanta: Centers for Disease Control and Prevention; 1994.

19. Tello O, Heras CA, Pachón I, Martínez JF. Vigilancia de la Salud. En: Martínez F, Antó JM, Castellanos PL, Gili M, Marset P, Navarro V, editores. Salud Pública. México: Mc Graw-Hill Interamericana; 2002. p.435-63.

20. Agudelo Cl, Muñoz N, De la Hoz F. Evaluación rápida del impacto de la vacuna contra Haemophilus influenzae serotipo b en Colombia. Laboratorios de Salud Pública. Rev Panam Salud Publica 2000;8:181-4.

21. Fenoll A, Jado I, Vicioso D, Berrón S, Yuste JE, Casal J. Streptococcus pneumoniae in children in Spain: 1990-1999. Acta Paediatr Suppl 2000;89:44-50.

22. Kaltoft MS, Zeuthen N, Konradsen HB. Epidemiology of invasive pneumococcal infections in children aged 0-6 years in Denmark. Acta Paediatr Suppl 2000;89:310.

23. Kapplan SL, Mason EO Jr, Wald E, Tan TQ, Schutze GE, Bradley JS, et al. Six years multicenter surveillance of invasive pneumococcal infections in children. Pediatr Infect Dis J 2002;21:141-7.

24. Lagos R, Muñoz A, Valenzuela MT, Heitmann I, Levine MM. Population-based surveillance and ambulatory pediatric invasive pneumococcal disease in Santiago, Chile. Pediatr Infect Dis J 2002;21:111523.

25. Casado Flores J, Fenoll A, Aristegui Fernández J, Rodrigo de Liria C, Martinón Sánchez JM, Berron $\mathrm{S}$, et al. Meningitis neumocócica en niños españoles: incidencia, serotipos y resistencia antibiótica. Estudio prospectivo multicéntrico. An Esp Pediatr 2002;57:295300.

26. Berezin EN, Carvalho LH, Lopes CR, Sanajotta AT, Brandileone MC, Menegatti S, et al. Pneumococcal meningitis in children: clinical findings, most frequent serotypes and outcome. J Pediatr 2002;78:19-23.

27. Brandileone MC, de Andrade AL, Di Fabio JL, Guerra ML, Austrian R. Appropriateness of 
pneumococcal conjugate vaccine in Brazil: potential impact of age and clinical diagnosis, with emphasis on meningitis. J Infect Dis 2003;187:1206-12.

28. Inostroza J, Vinet AM, Retamal G, Lorca P, Ossa G, Facklam RR, et al. Influence of patient age on Streptococcus pneumoniae serotypes causing invasive disease. Clin Diagn Lab Immunol 2001;8:556-9.

29. Hoffman JA, Mason EO, Schutze GE, Tan TQ, Barson WJ, Givner LB, et al. Streptococcus pneumoniae infections in the neonate. Pediatrics 2003;112:1095-102.

30. Gomez M, Alter S, Kuman ML, Murphy S, Rathore MH. Neonatal Streptococcus pneumoniae infection: case reports and review of literature. Pediatr Infect Dis J 1999;18:1014-8.

31. Fenoll A, Asencio G, Jado I, Berrón S, Camacho MT, Ortega M, et al. Antimicrobial susceptibility and pneumococcal serotypes. J Antimicrob Chemother 2002;50(Suppl. 2):13-9.

32. Fenoll A, Jado I, Vicioso D, Pérez A, Casal J. Evolution of Streptococcus pneumoniae serotypes and antibiotic resistance in Spain: update (1990 to 1996). J Clin Microbiol 1998;36:3447-54.

33. Baquero F, Baquero-Artigao G, Canton R, GarcíaRey C. Antibiotic consumption and resistance selection in Streptococcus pneumoniae. J Antimicrob Chemother 2002;50(Suppl. 2):27-37.

34. Hsueh PR, Teng LJ, Lee LN, Yang PC, Ho SW, Luh KT. Extremely high incidence of macrolide and trimethoprim-sulfamethoxazole resistance among clinical isolates of Streptococcus pneumoniae in Taiwan. J Clin Microbiol 1999;37:897-901.

35. File TM Jr. Appropriate use of antimicrobials for drugresistant pneumonia: focus on the significance of $b$ lactam-resistant Streptococcus pneumoniae. Clin Infect Dis 2002;34(Suppl 1):S17-S26.

36. García-Rey C, Bouza E, Aguilar L, García-de-Lomas $J$, Baquero F, Spanish Surveillance Group for Respiratory Pathogens. Evolution of penicillin and erythromycin co-resistance in Streptococcus pneumoniae in Spain. Int J Antimicrob Agents 2003;22:541-4.

37. Fedman C. Clinical relevance of antimicrobial resistance in the management of pneumococcal community-acquired pneumonia. J Lab Clin Med 2004;143:269-83.

38. Doern GV. Antimicrobial use and emergence of antimicrobial resistance with Streptococcus pneumoniae in the United States. Clin Infect Dis 2001;33(Suppl 3):S187-92.

39. McGee L, McDougal L, Zhou J, Spratt G, Tenover FC, George R, et al. Nomenclature of major antimicrobial-resistant clones of Streptococcus pneumoniae defined by the pneumococcal molecular epidemiology network. J Clin Microbiol 2001;39:256571.

40. The Pneumococcal Molecular Epidemiology Network, PMEN. Pagina de internet. [Consultado: junio 05 de 2005]. Disponible en http://www.sph.emory.edu/ PMEN/.

41. Parry CM, Duong NM, Zhou J, Hoang Mai N, Song T, Thinh LQ, et al. Emergence in Vietnam of Streptococcus pneumoniae resistant to multiple antimicrobial agents as a result of dissemination of the multiresistant Spain ${ }^{23 F}-1$ clone. Antimicrob Agents Chemother 2002;46:3512-7.

42. Echániz-Aviles G, Velázquez-Meza ME, CarnillaBarajas MN, Soto-Noguerón A, Di Fabio JL, Solórzano-Santos $\mathrm{F}$, et al. Predominance of the multiresistant 23F international clone of Streptococcus pneumoniae among isolates from México. Microb Drug Resist 1998;4:241-6.

43. Camou T, Hortal M, Tomasz A. The apparent importation of penicillin-resistant capsular type 14 Spanish/French clone of Streptococcus pneumoniae into Uruguay in the early 1990s. Microb Drug Resist 1998;4:219-24.

44. Rossi A, Corso A, Pace J, Regueira M, Tomasz A. Penicillin-resistant Streptococcus pneumoniae in Argentina: frequent occurrence of an internationally spread serotype 14 clone. Microb Drug Resist 1998;4:225-31.

45. Serrano I, Melo-Cristino J, Carric JA, Ramirez M. Characterization of the genetic lineages responsible for pneumococcal invasive disease in Portugal. J Clin Microbiol 2005;43:1706-15.

46. Greenberg D, Dagan R, Muallem M, Porat N. Antibiotic-resistant invasive pediatric Streptococcus pneumoniae clones in Israel. J Clin Microbiol 2003;41:5541-5.

47. Tamayo M, Sá-Leao R, Santos Sanches I, Castañeda E, de Lencastre H. Dissemination of a chloramphenicol and tetracycline-resistant but penicillin-susceptible invasive clone of serotype 5 Streptococcus pneumoniae in Colombia. J Clin Microbiol 1999;37:2337-42.

48. Gamboa L, Camou T, Hortal M, Castañeda E, Sireva-Vigia Working Group. Dissemination of Streptococcus pneumoniae clone Colombia 5 -19 in Latin America. J Clin Microbiol 2002;40:3942-50.

49. De la Hoz F. Introducción en Colombia de la vacuna conjugada contra Streptococcus pneumoniae. Inf Quinc Epidemiol Nac 2001;6:1-2.

50. Whitney CG. Impact of conjugate pneumococcal vaccines. Pediatr Infect Dis J 2005;4:729-30.

51. Lucarevschi BR, Baldacci ER, Bricks LF, Bertoli CJ, Teixeira LM, Mendes CM, et al. Oropharyngeal carriage of Streptococcus pneumoniae by children attending day care centers in Taubaté, SP: correlation 
between serotypes and the conjugated heptavalent pneumococcal vaccine. J Pediatr 2003;79:215-20.

52. Hortal M, Palacio R, Camou T, Albini M. Neumococcias en niños hospitalizados: serotipos capsulares y resistencia a los antibióticos. En: Avances Multidisciplinarios para el control integral de Streptococcus penumoniae. Uruguay diez años de experiencia. Washington: OPS; 2004. p.51-64.

53. Talbot TR, Poehling KA, Hartert TV, Arbogast PG, Halasa NB, Mitchel E, et al. Reduction in high rates of antibiotic-nonsusceptible invasive pneumococcal disease in Tennessee after introduction of the pneumococcal conjugate vaccine. Clin Infect Dis 2004;39:641-8.

54. Huang SS, Platt R, Rifas-Shiman SL, Pelton SI, Goldmann D, Finkelstein JA. Post-PCV7 changes in colonizing pneumococcal serotypes in 16 Massachusetts communities, 2001 and 2004. Pediatrics 2005;116;408-13.

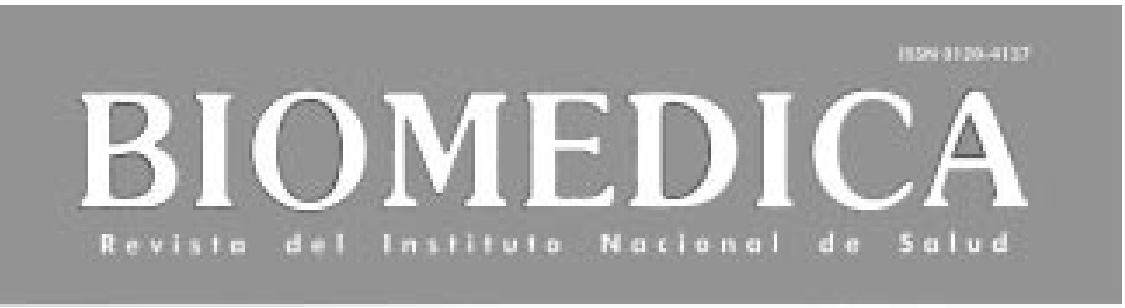

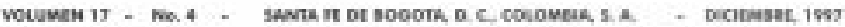

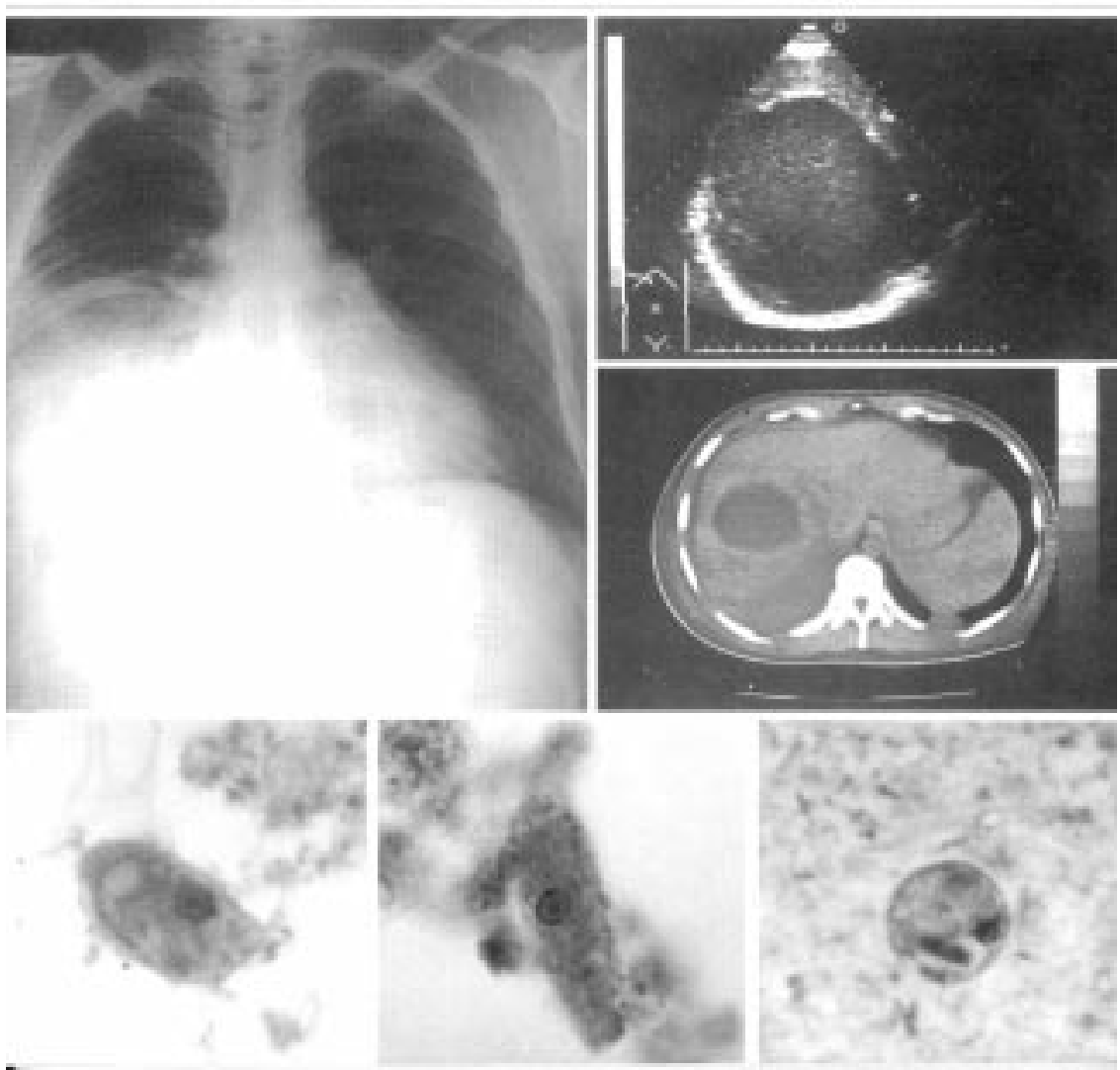

